\title{
IV CiNCCI - Colóquio internacional SOBRE COMÉRCIO E CIDADE: UMA RELAÇÃO DE ORIGEM
}

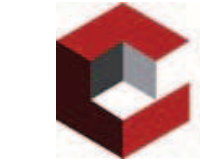 \\ $\mathrm{CINCCI}$ \\ IV Colóquio Internacional \\ sobre o comiercio e cidade: uma relacklo de origem}

\author{
Heliana Comin Vargas
}

Os Colóquios Internacionais sobre Comércio e Cidade, iniciativa do Laboratório de Comércio e Cidade, junto ao Departamento de Projeto da Faculdade de Arquitetura e Urbanismo da Universidade de São Paulo, agora na sua quarta edição, têm como propósito estimular discussões e contribuir para a troca de idéias sobre o comércio e serviços, enquanto atividade econômica e social, e o seu rebatimento no território, na imagem da cidade e na paisagem urbana. Tem como finalidade reunir pesquisadores que têm se dedicado ao tema, buscando fortalecer esta área do conhecimento de caráter multidisciplinar, como forma de subsidiar a elaboração de políticas urbanas competentes que envolvam as áreas de usos comerciais e de serviços

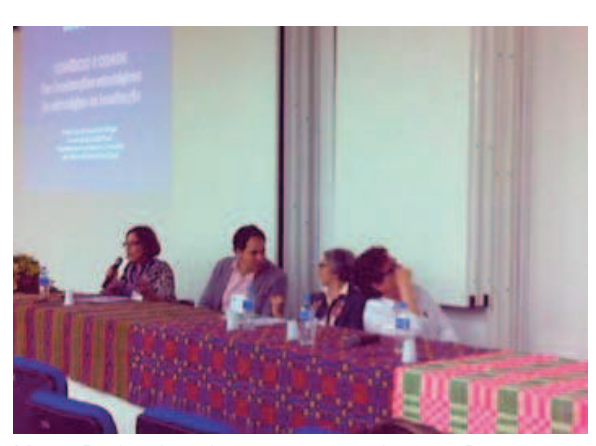

Mesa Redonda - Intervenções urbanas. Por quê e como intervir?

Foto: Simone Villa

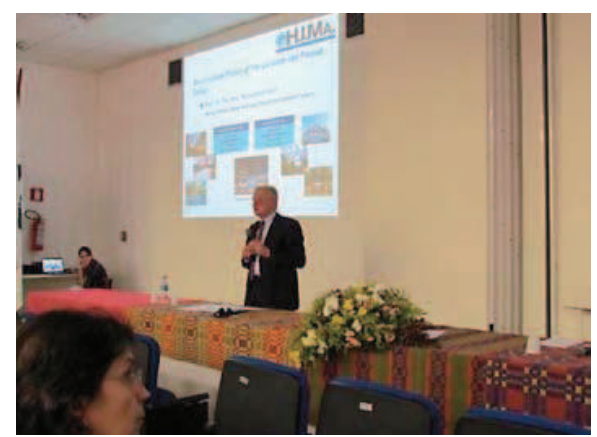

Conferência - Professor Joachin Zentes Foto: Heliana Comin Vargas
Nesta edição, o Colóquio foi sediado na cidade de Uberlândia, junto à Faculdade de Arquitetura e Urbanismo e Design da Universidade Federal de Uberlândia (UFU), coordenado pelo professor Fernando Garrefa.

Várias atividades foram programadas tendo o evento contado com a participação de pesquisadores, alunos e professores, provenientes de várias partes do Brasil, e de outros países, num total aproximado de 150 participantes presentes. 0 evento também se destacou pela diversidade dos pesquisadores, de várias áreas do conhecimento: geografia, história, antropologia, administração, design, turismo e arquitetura e urbanismo.

As conferências e a mesa redonda com palestrantes nacionais e internacionais tiveram um papel fundamental nas discussões por aproximar o desenvolvimento comercial à intervenção urbana, aos negócios do varejo e à arquitetura voltada ao uso comercial.

Para a mesa redonda "Intervenções urbanas: Porquê e Como intervir?" contamos com a Presença da professora Heliana Comin Vargas, da FAUUSP, professora Tereza Barata Salgueiro, do Centro de Estudos Geográficos da Universidade de Lisboa, professor José de Souza Brandão Neto, da UFPE, e a coordenação do professor Fernando Garrefa, da UFU.

A conferência Internacional "Trends in European Retailing: The Comeback of the City?" pelo professor Joachin Zentes, Gestão e Marketing Internacional na Universidade de Saarland, Alemanha. 
A conferência Institucional foi realizada pelo arquiteto Antonio Dias Neto, da General Shopping, sobre o título "O Shopping Light em São Paulo: requalificação urbana, proteção do patrimônio e viabilidade comercial"

As sessões temáticas foram distribuídas em sessões únicas e sessões paralelas. As sessões únicas buscaram concentrar temas de interesse comum como os aspectos socioculturais do comércio. As sessões paralelas apresentaram temas como requalificações urbanas e centralidades, preservação urbana e comércio; turismo e produção do espaço; arquitetura comercial e design, enfatizando o caráter transdisciplinar desta área do conhecimento.

Houve ainda a sessão "Conversa com os autores" onde foram apresentados os seguintes livros:

OLIVEIRA, Cláudia Leonor; WORCMAN, Karen; RUIZ, Márcia. Comercio em São Paulo: histórias e imagens da cidade e Memórias do comercio paulista: Guia de acervo. São Paulo SESC/Museu da Pessoa, 2013

BRAIDA, Frederico. Passagens em Rede. A dinâmica das galerias comerciais e dos calçadões nos centros de Juiz de Fora e Buenos Aires. Juiz de Fora: FINALPA. 2012. BRANDÃO NETO, José de Souza. Núcleo Técnico de Operações Urbanas: estudos 2007-2010". Recife, CEPE, 2012.

GARREFA Garrefa. Shopping Centers. De centro de abastecimento a produto de consumo. São Paulo: SENAC. 2011.

DEMETRESCO, Sylvia; REGAMEY, Rita. Tipologia e estética do Visual Merchandising. Estação das letras e cores. 2012

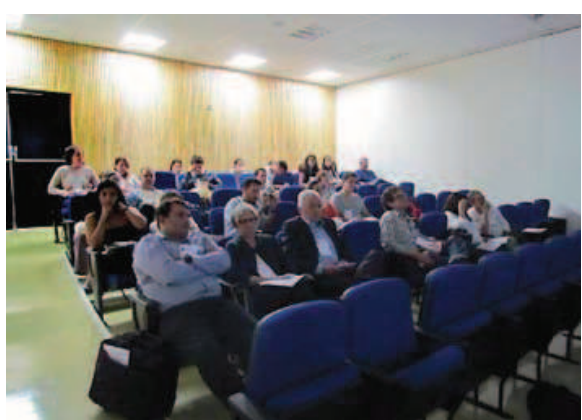

Sessão "Conversa com os autores" com a presença dos palestrantes. Foto: Heliana Comin Vargas

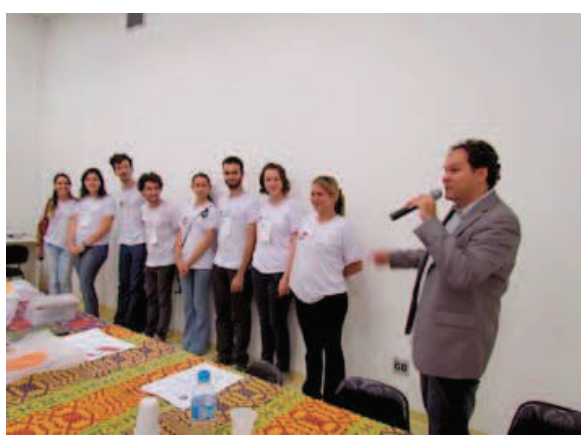

Sessão de premiação e encerramento Foto: Heliana Comin Vargas

Houve ainda a sessão de relatos dos coordenadores de mesa das sessões temáticas do evento, possibilitando uma visão geral dos trabalhos apresentados.

Para além das conferências e apresentação de trabalhos e livros, o evento realizou outras atividades:

- Uma visita técnica ao Centro de Distribuição Martins, líder no segmento do atacado distribuidor brasileiro e uma referência na distribuição e no varejo do País, possibilitando aos participantes conhecer as instalações e informar-se sobre os processos de operação do sistema.

- O leilão de livros repete novamente o seu êxito aproveitando-se do espírito da troca. Livros da área foram doados por autores e participantes e leiloadas ao preço da oportunidade gerada. Dentro de cada livro foi colocado uma folha onde pudessem ser feitas as ofertas. Em um determinado momento anunciou-se o final do leilão e as maiores ofertas arremataram os respectivos livros, sempre preços muito simbólicos. É uma experiência interessante, de divulgação, de oportunidade de compra e de troca entre os participantes.

- A premiação dos melhores trabalhos indica, mais uma vez, a amplitude desta área do conhecimento, conforme pode ser observado a seguir.

$1^{0}$ Reflexões acerca da descentralização do comércio MARASCHIN, Clarice.

$2^{0}$ - Conceituações de Diferentes Subgrupos sobre a

Paisagem Urbana Midiática

COSTA FILHO, Lourival Lopes; MONTEIRO, Circe M. G. 
UFU - Exposição "O lugar do mercado e a imagem da troca"

Fotos: Heliana Comin Vargas
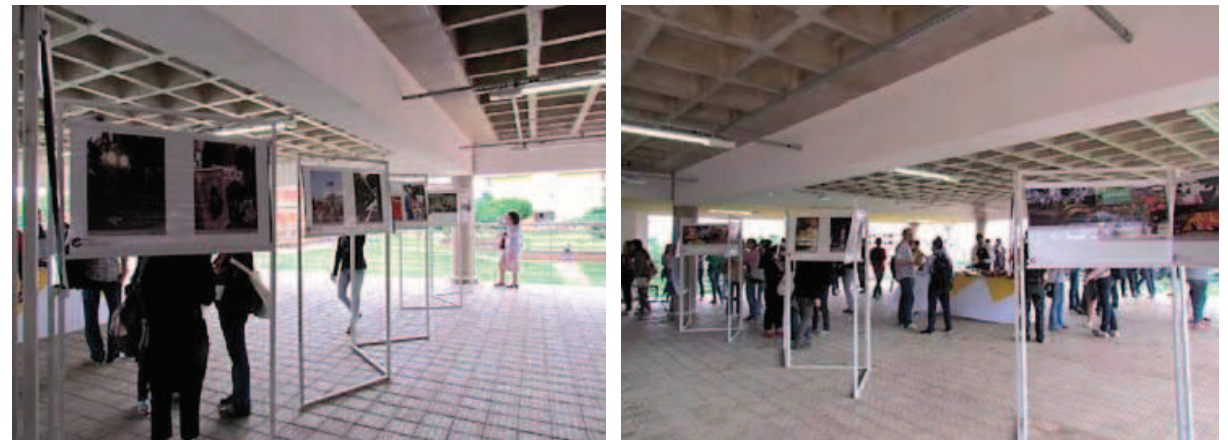

$3^{0}$ - Comércio noturno em Juiz de Fora/MG: dinâmicas do espaço público e da vida urbana

COLCHETE FILHO, Antonio; BRAIDA, Frederico; FONSECA, Fábio CARDOSO, Carina; TEODORO, Larissa;

$4^{0}$ - Projetos para o Centro Comercial de Aracaju: Palavras Repetidas SILVA, César Henriques Matos e.

- A exposição e II concurso fotográfico tiveram como finalidade provocar um olhar diferenciado sobre o ato da troca, ampliando a sua dimensão sóciocultural. Neste ano recebemos 34 imagens, que foram expostas durante 0 evento. A forma de eleição das três melhores imagens foi realizada pelos participantes do evento, de forma bastante participativa, considerando que 0 objetivo não era a qualidade técnica das imagens e sim o olhar sobre a troca.

FOTOS PREMIADAS
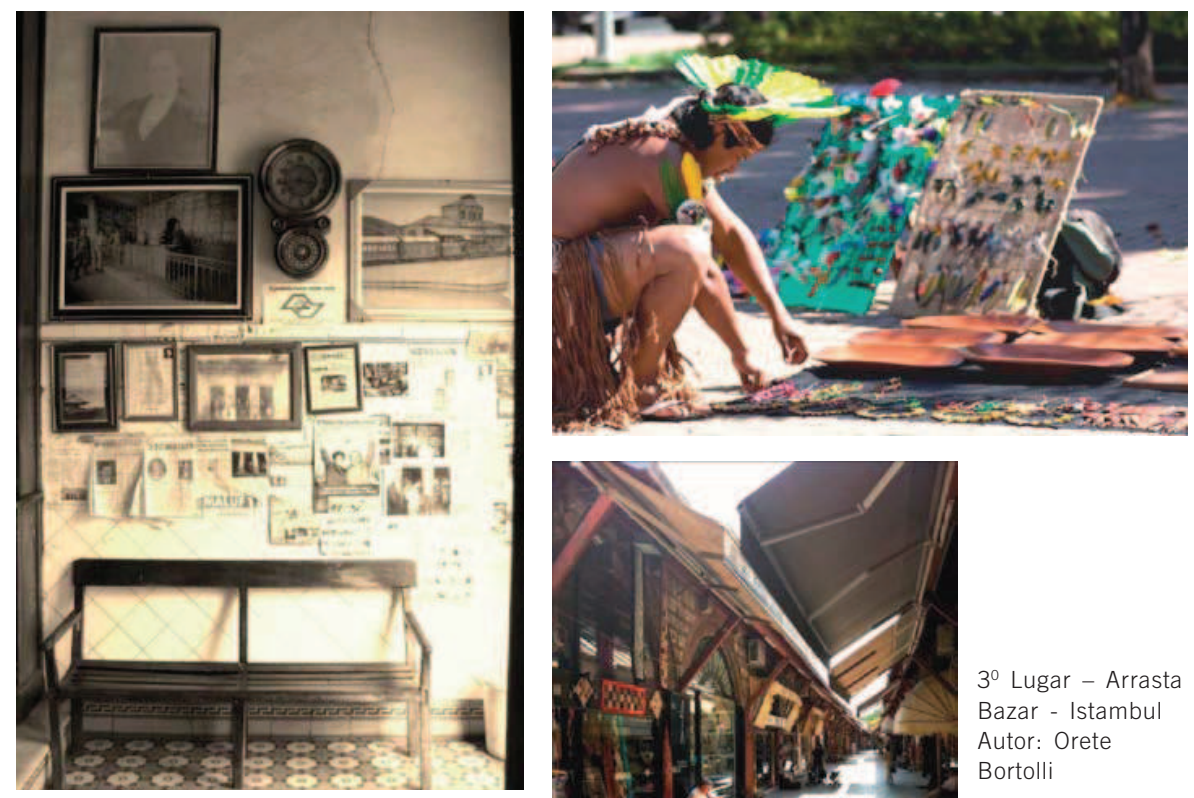

$2^{0}$ Lugar - A cultura indígena e o capitalismo Autor: Geise

Brisotti

Pasquotto

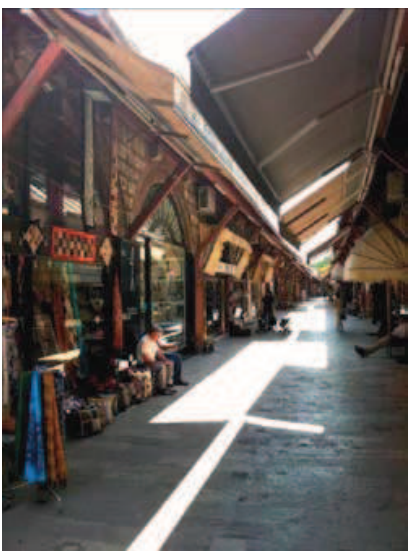

$3^{0}$ Lugar - Arrasta

Bazar - Istambul

Autor: Orete

Bortolli

Lugar - Pharmacia Popular

Autor: Tania Rajczuc Tombi 
Houve grande participação na escolha e foram indicadas as três melhores fotos

Os anais, em CD ROM, com ISBN, contêm os trabalhos aprovados pelos pareceristas para apresentação oral e que fizeram inscrição no evento.

As manifestações orais dos participantes apontam, mais uma vez, para o êxito do evento, mostrando que ele tem respondido plenamente às expectativas dos participantes, seja pelo conteúdo inovador e instigante; seja pela qualidade dos trabalhos e da distribuição das atividades e pela transdisciplinariedade temática.

Com estas atividades, estamos fortalecendo núcleos de pesquisa em outros estados brasileiros com lideranças na área de comércio e cidade.

Este evento, uma iniciativa do Laboratório de Comércio e Cidade (LabCom), junto ao Departamento de Projeto da FAUUSP, foi sediado neste ano pela UFU, que coordenou a organização do evento, contando com as seguintes Instituições organizadoras:

Laboratório de Comércio e Cidade (LabCom - FAUUSP)

Laboratorio Urb\&Com Politecnico di Milano

Universidade Estadual de Londrina (UEL),

Universidade Federal de Juiz de Fora (UFJF),

Universidade Federal de Uberlândia (UFU),

Universidade Federal do Ceará (UFC),

Universidade Federal do Rio Grande do Sul (UFRGS),

Realização: 26 a 28 de março de 2013

Faculdade de Arquitetura e Urbanismo e Design da UFU

Laboratório de Comércio e Cidade - LabCom - FAUUSP

www.usp.br/fau/depprojeto/labcom

labcom@usp.br

www.comercioecidade.com

COMISSÃO ORGANIZADORA

Fernando Garrefa, UFU (coordenação)

Ana Paula Preto, FAUUSP

Clarice Maraschin, URGS

Corinna Morandi, URBCOM

Eloísa Ramos Ribeiro Rodrigues, UEL

Frederico Braida, UFJF

Heliana Comin Vargas, FAUUSP

Ricardo Alexandre Paiva, UFC

Heliana Comin Vargas (relatora)

Chefe do Departamento de Projeto da FAUUSP, professora da Graduação e

Pós-Graduação e coordenadora do LabCom

Rua do Lago, 876 - Cid. Universitária

05508-080 - São Paulo, SP, Brasil

(11)3091-4535

labcom@usp.br 